\title{
PREMATURE BIRTH AND SUBSEQUENT ADMISSION TO HOSPITAL
}

\author{
BY \\ S. T. WINTER AND W. MAINZER \\ From the Department of Paediatrics, Rothschild Municipal Hospital, Haifa, Israel
}

It is recognized that premature birth is a major factor in neonatal mortality, and that prolonged care of such cases in new-born nurseries or premature units is advisable. There is also a growing realization that premature babies who are eventually discharged from the units remain handicapped for some months, possibly years, presumably because they are weaker than average and more susceptible to disease, especially infection. Certainly large numbers of children admitted to the paediatric wards of the Rothschild Hospital in Haifa weighed less than $2,500 \mathrm{~g}$. at birth, and the object of the present investigation was to discover the strength of the association between these low birth weights and subsequent admission to this hospital. The problem demands a "longitudinal study", with detailed follow-up of babies after their discharge from premature units; however, an assessment of the frequency of low birth weight among infants admitted to a paediatric department which serves the general community provides a relatively simple and rapid method of measuring the association between premature delivery and subsequent ill-health, provided, as is the case in Israel, few children die outside hospital and the vast majority of serious childhood diseases are treated in hospital. By repeating such an investigation at regular intervals, it would also be possible to discover if the special needs of premature babies are being met by existing health and welfare services. So far as we are aware, this is the first "cross-sectional" study of the problem to be reported.

In the following account, the birth weights of 998 children admitted to the Paediatric Department of the Rothschild Hospital will be examined.

\section{Material and Plan of Study}

The case-sheets of 998 consecutive admissions of children between the age of one month and 2 years during the period 1954-58 were collected. The birth weights, sex, death rates, and maturity status (above or below 2,500 g.) of these children are given in Table I. The age at admission is recorded in halfyears. No child under the age of one month was included because this is a period of exceptionally heavy mortality among premature babies. The discharge diagnoses of these children are given in Table II, and re-admissions in Table III. As the families from which prematures and full-term children were derived presented no great differences in socio-economic status, this will not be considered

\section{RESULTS}

Table I shows that 16.7 per cent. of the 998 patients admitted were ex-prematures, this percentage reaching 20.8 per cent. for those between 1 and 6 months old. The overall mortality rates for the premature and full-term children were the same (6.4 per cent.), but for children admitted at the age of 1 month to 1 year they were slightly higher for the prematures $(7.8$ per cent.) than for the full-term children $(5 \cdot 3$ per cent.). No significant difference was noted in the distribution by age at admission of the two birth-weight groups of prematures, but 45 per cent. of the full-term admissions were females, as compared with 50 per cent. of the prematures.

TABLE I

DETAILS OF 998 CONSECUTIVE ADMISSIONS OF CHILDREN BETWEEN 1 AND 24 MONTHS OF AGE

\begin{tabular}{|c|c|c|c|c|c|c|}
\hline \multicolumn{2}{|c|}{ Age at Admission (mths) } & $1-6$ & $7-12$ & 13-18 & $19-24$ & Total \\
\hline \multirow{2}{*}{$\begin{array}{l}\text { Maturity } \\
\text { Status } \\
\text { at Birth }\end{array}$} & Premature. . & 103 & 43 & 11 & 10 & 167 \\
\hline & Full-term .. & 391 & 253 & 122 & 65 & 831 \\
\hline \multirow{2}{*}{$\begin{array}{c}\text { Death } \\
\text { in } \\
\text { Hospital }\end{array}$} & Premature. . & 8 & 3 & - & - & 11 \\
\hline & Full-term .. & 21 & 13 & 4 & 1 & 53 \\
\hline \multirow{2}{*}{$\begin{array}{l}\text { Weight at Birth } \\
\text { (prematures } \\
\text { only) (g.) }\end{array}$} & Under 2,000 & 21 & 10 & 1 & 2 & 34 \\
\hline & $2,000-2,500$ & 82 & 33 & 10 & 8 & 133 \\
\hline \multirow{2}{*}{ Males } & Premature.. & 54 & 18 & 6 & 6 & 84 \\
\hline & Full-term .. & 229 & 136 & 62 & 30 & 457 \\
\hline
\end{tabular}


The reasons for admission are stated in Table II, where it will be seen that deficiency conditions (mainly rickets, anaemia, and malnutrition) were more frequent among prematures $(43 \cdot 1$ per cent.) than among full-term children $(25 \cdot 1$ per cent.). Readmission (Table III) was more frequent among prematures than full-term children, and the excess was greatest among the children who were first admitted at the age of 1 to 6 months.

TABLE II

DISTRIBUTION OF MAJOR DISEASE GROUPS

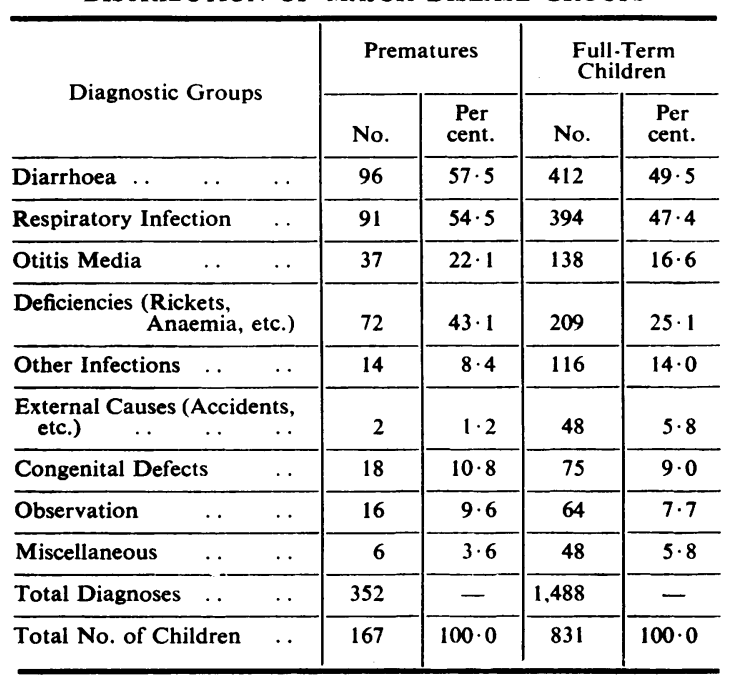

TABLE III

RE-ADMISSIONS TO HOSPITAL OF PREMATURE AND FULL-TERM BABIES

\begin{tabular}{|c|c|c|c|c|}
\hline \multirow{3}{*}{$\begin{array}{c}\text { Age at First } \\
\text { Admission } \\
\text { (mths) }\end{array}$} & \multicolumn{4}{|c|}{ Re-admissions } \\
\hline & \multicolumn{2}{|c|}{ Prematures } & \multicolumn{2}{|c|}{ Full-Term Children } \\
\hline & No. & Per cent. & No. & Per cent \\
\hline $\begin{array}{l}1-6 \\
-12 \\
-18 \\
-24\end{array}$ & $\begin{array}{r}31 \\
19 \\
5 \\
5\end{array}$ & $\begin{array}{l}30 \cdot 0 \\
44 \cdot 1 \\
45 \cdot 4 \\
50 \cdot 0\end{array}$ & $\begin{array}{l}59 \\
75 \\
35 \\
24\end{array}$ & $\begin{array}{l}14 \cdot 7 \\
29 \cdot 0 \\
28 \cdot 2 \\
36 \cdot 3\end{array}$ \\
\hline $\begin{array}{l}\text { Total Re-admissions } \\
\text { Original No. of } \\
\text { Children }\end{array}$ & $\left.\begin{array}{r}60 \\
167\end{array}\right\}$ & $35 \cdot 9$ & $\left.\begin{array}{l}193 \\
831\end{array}\right\}$ & $22 \cdot 7$ \\
\hline
\end{tabular}

\section{Discussion}

Recent surveys have shown that the percentage of premature births in Israel has ranged from 4.7 to $7 \cdot 1$ (Halevi, 1959), and the relatively high neonatal death-rate among prematures has probably reduced the percentage of prematures over the age of one month in the community to well below 7 per cent. It follows from this that the morbidity experience of our premature group has been unduly great, especially in the first half-year of life, where prematures represented 20.8 per cent. of all such admissions.

The absence of significant differences in mortality rates in the two groups suggests that the illnesses acquired by prematures were no more dangerous to them than to full-term children, providing adequate treatment was given. Most illnesses requiring admission to hospital were infectious in origin, but there is no evidence that in this respect the premature children were at a disadvantage when compared with full-term children.

The high proportion of prematures with birth weights between 2,000 and $2,500 \mathrm{~g}$. suggests that even babies who are only slightly underweight at birth retain a health handicap for prolonged periods.

It is common experience that male admissions to paediatric wards outnumber female admissions (Poulton, 1923; Tisdall, Brown, and Kelly, 1930), and the equal sex distribution among premature children in the present series is probably due to the greater frequency of low birthweights among females (Halevi, 1959).

The higher incidence of deficiency conditions, especially rickets and anaemia, among prematures was to be expected. However, there was not a significantly greater incidence of respiratory infections in the premature group, as was noted by other authors (Drillien, 1959; Douglas and Mogford, 1953). Otitis media was never a reason for admission in this series.

On so general and important a problem as the health of premature children, the available recent literature is relatively scanty. Drillien (1959) reported an accurate and comprehensive longitudinal study of premature and full-term children and noted that hospital admissions of prematurely-born children during the first 2 years of life were $2 \frac{1}{2}$ times higher than those of a control group, and Alm (1953) also found relatively high death rates in prematures during the first 2 years of life. In this study prematures surviving 2 to 3 years showed no difference in the incidence of major disease as compared with mature infants, with the exception of a higher frequency of disorders related to birth injury. Douglas and Mogford (1953) compared the health of premature children with that of full-term controls during the first 4 years of life, and found a much higher incidence of hospital admissions, especially for bronchitis and pneumonia, during the first 2 years of life. These premature children spent on the average $3 \frac{1}{2}$ times as many days in hospital during the first 2 years of life as the controls. The average stay 
per illness was greater for prematures, and there was also a marked relationship between the birth weight of premature children and the likelihood of their being admitted to hospital, males, both premature and controls, being more likely to be admitted than females, and lung infections being more common among the premature children. Crosse (1954) confirmed the excessive death rate from congenital defects and infections among prematures during the first 2 to 3 years of life and commented on their increased susceptibility to infections during the first 2 years. Perkins (1955) recorded 239 illnesses in a one-year follow-up study of 144 prematures, and 138 of these illnesses were infectious in origin, mainly of the respiratory tract; in this series 27 children were admitted to hospital and 52 per cent. of these illnesses were the results of infection or malnutrition and assumed to be preventable. Of the 212 illnesses not requiring admission to hospital, 55 per cent. (infections, accidents, and malnutrition) were regarded as preventable. Newsom and Pesut (1958) re-examined 280 babies weighing less than $2,000 \mathrm{~g}$. at birth at the age of 1 year, and found a death rate of 5.9 per cent. during the period after discharge from hospital. Levy (1958) reviewed 117 premature infants 10 months after discharge from a premature unit in Israel and discovered that eleven infants had died and 32 others had been admitted to hospital. James (1958) found an excessively high death rate among prematures as compared with full-term infants, and discovered that the chief cause of death was infection. In this series there was a high rate of morbidity during the first 2 years of life and one-quarter of the children in this age group required admission to hospital. The morbidity was highest among children with lower birth weights, and 60 per cent. of the hospital admissions were due to respiratory infections or diarrhoea, with or without anaemia and malnutrition. A further 10 per cent. of the admissions were for accidents, including poisoning.

The present investigation shows that children who are born prematurely represent a high proportion of all children requiring hospital treatment. It is possible that the original requests for their admission were influenced more by the low birth weight than the immediate clinical state, but the numbers are too great to be explained in this way and all the children were re-examined before they were actually admitted to the wards. Naturally, of two "equivalently sick" children, the small one would usually be given priority of admission, but whatever the grounds for requesting or confirming admission, the fact remains that in comparison with their numbers in the general population, prematurely-born children were admitted to hospital more than twice as frequently as full-term children.

The need for further study of the later health of premature infants has been stressed by James (1958), and the present investigation confirms his suspicion that the increased susceptibility of prematures to illness, especially infection, persists at least up to the age of 2 years. Since hospital treatment is expensive and potentially dangerous to young children, the reduction in admissions of prematurely-born children represents a specific challenge in this field. Concentration of child health measures on all prematures throughout the first 2 years of life, possibly by special public health nurses, might reduce appreciably the work of hospital paediatric units and is urgently called for for other reasons.

\section{SUMMARY}

Out of 998 children from 1 to 24 months of age admitted to a general paediatric department, 16.7 per cent. had a birth weight of $2,500 \mathrm{~g}$. or less. $U p$ to the age of 6 months the percentage of prematures was 20.8 per cent. These figures are much above the frequency of prematurity in the general community (which is less than 7 per cent.) and show that the premature maintains an increased susceptibility to illness, especially infection, throughout the first 2 years of life. The relation between prematurely-born children and paediatric hospitalization needs is discussed.

We are indebted to Professor S. Ehrenfeld of the Israel Institute of Technology for statistical advice, to Dr. B. Ostrowski for much of the clinical material, and to the van Leer Foundation for a publication grant.

\section{REFERENCES}

Alm, 1. (1953). Acta paediat., 42, Suppl. 94, p. 59.

Crosse, V. M. (1954). Amer. J. Publ. Hlth, 44, 1010

Douglas, J. W. B., and Mogford, C. (1953). Brit. med. J., 1, 748

Drillien, C. M. (1958). Arch. Dis. Childh., 34, 210.

Halevi, H. S. (1959). Harefuah, 56, 205.

James, J. A. (1959). Pediatrics, 22, 154.

Levy, I. (1958). Personal communication.

Newsom, W. T., and Pesut, L. (1958). Amer. J. Dis. Child., 96, 632

Perkins, G. B. (1955). Amer. J. Publ. Hlth, 45, 774.

Poulton, E. M. (1950). Arch. Dis. Childh., 25, 392. Tisdall, F. F.; Brown, A., and Kelly, A. D. (1930). Amer. J. Dis.
child., 39, 163. 